\title{
Doxorubicin persistently rewires cardiac circadian homeostasis in mice
}

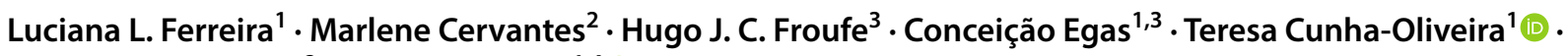 \\ Paolo Sassone-Corsi ${ }^{2} \cdot$ Paulo J. Oliveira ${ }^{1,4}$ (B)
}

Received: 5 September 2019 / Accepted: 13 November 2019

(c) Springer-Verlag GmbH Germany, part of Springer Nature 2019

\begin{abstract}
Circadian rhythms disruption can be the cause of chronic diseases. External cues, including therapeutic drugs, have been shown to modulate peripheral-circadian clocks. Since anthracycline cardiotoxicity is associated with loss of mitochondrial function and metabolic remodeling, we investigated whether the energetic failure induced by sub-chronic doxorubicin (DOX) treatment in juvenile mice was associated with persistent disruption of circadian regulators. Juvenile C57BL/6J male mice were subjected to a sub-chronic DOX treatment (4 weekly injections of $5 \mathrm{mg} / \mathrm{kg}$ DOX) and several cardiac parameters, as well as circadian-gene expression and acetylation patterns, were analyzed after 6 weeks of recovery time. Complementary experiments were performed with Mouse Embryonic Fibroblasts (MEFs) and Human Embryonic Kidney 293 cells. DOXtreated juvenile mice showed cardiotoxicity markers and persistent alterations of transcriptional- and signaling cardiac circadian homeostasis. The results showed a delayed influence of DOX on gene expression, accompanied by changes in SIRT1-mediated cyclic deacetylation. The mechanism behind DOX interference with the circadian clock was further studied in vitro, in which were observed alterations of circadian-gene expression and increased BMAL1 SIRT1-mediated deacetylation. In conclusion, DOX treatment in juvenile mice resulted in disruption of oscillatory molecular mechanisms including gene expression and acetylation profiles.
\end{abstract}

Keywords Doxorubicin $\cdot$ Chemotherapy $\cdot$ Cardiotoxicity $\cdot$ Circadian clock $\cdot$ Mitochondria $\cdot$ Protein acetylation

Electronic supplementary material The online version of this article (https://doi.org/10.1007/s00204-019-02626-z) contains supplementary material, which is available to authorized users.

Paulo J. Oliveira

pauloliv@cnc.uc.pt

1 Mitochondrial Toxicology and Experimental Therapeutics Laboratory (MitoXT), CNC, Center for Neuroscience and Cell Biology, University of Coimbra, UC Biotech Building (Lote 8A), Biocant Park, 3060-197 Cantanhede, Portugal

2 Department of Biological Chemistry, Center for Epigenetics and Metabolism, University of California, Irvine, CA 92697, USA

3 Next Generation Sequencing Unit, Biocant, Biocant Park, Núcleo 04, Lote 8, Cantanhede, Portugal

4 Institute for Interdisciplinary Research (I.I.I.), University of Coimbra, Coimbra, Portugal

\section{Introduction}

Cardiovascular physiology and disease, including myocardial infarction and sudden cardiac death, exhibit a $24 \mathrm{~h}$ periodicity (Litinski et al. 2009; Mistry et al. 2017; Tsimakouridze et al. 2015). Rhythmic cardiac behavior indicates that the circadian clock is a relevant factor in the development of cardiac diseases, as well as a potential therapeutic target.

Daily oscillations are mostly controlled by transcriptional- and translational feedback-loops, although they are also driven by the interplay with cellular metabolism and energy status. One such example is $\mathrm{NAD}^{+}$-dependent sirtuin activity that is regulated by clock-driven $\mathrm{NAD}^{+}$biosynthesis (Nakahata et al. 2009). For example, SIRT3-activity rhythmicity is known for generating oscillations on the acetylation of key mitochondrial proteins (Peek et al. 2013), while SIRT1 binds the core clock proteins BMAL1:CLOCK in a rhythmic manner promoting deacetylation of clock proteins, histones, and proteins involved in metabolic- and apoptotic processes (Bellet et al. 2013; Nakahata et al. 2008; Sahar et al. 2014). Recent findings demonstrate that the internal 
clocks are coordinated in their metabolism, suggesting communication between circadian oscillators (Dyar et al. 2018). Disturbing these communication pathways and the desynchronization between the central pacemaker, located in the suprachiasmatic nucleus, and peripheral clocks are associated with several diseases (Litinski et al. 2009; West et al. 2017; Young and Bray 2007). Mice exposed to unusual light-dark (LD) cycles, similarly to shift workers, present altered metabolic efficiency and substrate utilization, as well as depressed cardiac function (West et al. 2017). While circadian disruptions are deleterious for the normal heart function (Knutsson et al. 1986; Kohsaka et al. 2014), NAD ${ }^{+}$and SIRT1 seem to protect the myocardium against aging and oxidative stress (Alcendor et al. 2007; Mericskay 2016).

Based on these notions we sought to investigate whether pharmaceutical alterations of the cardiac circadian machinery may result in an increased incidence of cardiovascular disease. To explore drug effects in cardiac rhythms, we used doxorubicin (DOX) as a cardiotoxic agent.

DOX is a very efficient antineoplastic drug with severe cardiac side-effects that limit its clinical utilization (Carvalho et al. 2014). Children are particularly vulnerable to post-treatment DOX side-effects and caution needs to be taken not only during treatment or shortly after, but also during long-term follow-up (Bansal et al. 2017). Persistent deleterious and chronic effects of DOX on the cardiovascular system may result in heart failure. In fact, it was estimated that $10 \%$ of children receiving a cumulative dose of $300 \mathrm{mg} /$ $\mathrm{m}^{2}$ or higher eventually experience heart failure during the 20 years after anthracycline therapy (van Dalen et al. 2006). In another cohort, the incidence of congestive heart failure associated with anthracycline treatment was more than fivefold higher at doses of $250 \mathrm{mg} / \mathrm{m}^{2}$ or more, compared with survivors who have not been exposed to anthracyclines (Mulrooney et al. 2009). The reasons for this persistency of effects have not yet been totally clarified even though several hypotheses have been addressed before, including mtDNA mutations with further perpetuation of defects on respiratory subunits encoded by mtDNA (Lebrecht et al. 2005), impaired-cardiac progenitor cells function and neovascularization (Huang et al. 2010), persistently-altered transcript levels (Berthiaume and Wallace 2007; Richard et al. 2011) or even altered DNA methylation (Nordgren et al. 2017).

Accumulating evidence suggests that DOX may interfere with the metabolic pathways controlled by sirtuins. In fact, resveratrol, a sirtuin activator, has shown promising results in the prevention of DOX-induced cardiotoxicity (Liu et al. 2016; Osman et al. 2013; Wang et al. 2012; Zhang et al. 2011). Some recent in vivo and in vitro studies observed decreased SIRT1 (Wang et al. 2017; Zhu et al. 2017) and SIRT3 (Cheung et al. 2015; Pillai et al. 2016) mRNA-expression and protein levels after DOX administration. Additionally, the metabolic shifts resultant from
cardiac-DOX exposure have also shown to alter mitochondrial pathways for ATP production that could ultimately result in dysregulated $\mathrm{NAD}^{+} / \mathrm{NADH}$ ratios and $\mathrm{NAD}^{+}$levels, important linkers with the circadian regulation (Heart et al. 2016; Wang et al. 2014).

The present study investigates whether DOX exposure in young mice could persistently interfere with the longterm transcriptional- and signaling circadian homeostasis, and how the metabolic- and energetic failure induced by a sub-chronic DOX treatment is integrated at the level of the circadian machinery.

\section{Methods}

\section{Animal care}

Animals and protocols were reviewed and approved by the Institutional Animal Care and Use Committee of the University of California, Irvine.

Wild-type male C57BL/6J mice of three weeks of age were obtained from Jackson Laboratory (Bar Harbor, ME, USA) and acclimated for 1 week prior the initiation of experiments. Animals were housed with ad libitum standard chow- and water access, under controlled temperature (24-25 $\left.{ }^{\circ} \mathrm{C}\right)$, humidity, and $12 \mathrm{~h}$ artificial light/dark cycle (12:12 LD). Animals were monitored daily by both the laboratory and University Lab Animal Resources veterinary staff. Cages (5 mice per cage) were cleaned weekly to maintain a clean environment.

\section{Experimental design}

C57BL/6J mice were randomly divided into two groups: SAL- and DOX treatment. One group received a total of $20 \mathrm{mg} / \mathrm{kg}$ of DOX (intra-peritoneal injection of $5 \mathrm{mg} / \mathrm{kg}$ in $0.9 \%$ saline solution, for 4 weeks), while the other control group received the equivalent volume of the vehicle salinesolution. Animals were injected during the light phase ( ZT 5), considering that the best tolerability to DOX in mice has been shown to be near the middle of the light phase (Granda et al. 2001; Sothern et al. 1989), and were weighed weekly before the injections. Two weeks prior sacrifice, the cages were moved into a strict 12:12 LD room. The animals were sacrificed by $\mathrm{CO}_{2}$ inhalation followed by cervical dislocation 6 weeks after the final DOX injection, at 4 different time-points (ZT 3, ZT 9, ZT 15, and ZT 21) (Supplemental Figure 1). Extraction of the heart was quickly performed, hearts were washed in PBS, weighed, the left ventricle carefully extracted, and flash frozen in liquid nitrogen. Heart ventricles were then kept at $-80{ }^{\circ} \mathrm{C}$. No mortality was observed during the experiment. 


\section{Cell culture and transfection}

HEK (Human Embryonic Kidney) 293 cells were cultured in $25 \mathrm{mM}$ glucose DMEM supplemented with $10 \%$ FBS and $1 \%$ Penicillin-Streptomycin, in $0.1 \%$ gelatin-coated dishes. The culture was maintained at $37{ }^{\circ} \mathrm{C}$ in a humidified atmosphere of $5 \% \mathrm{CO}_{2}$ and cells were passaged when reaching $80-90 \%$ of confluence. One day after seeding $\left(2.5 \times 10^{4}\right.$ cells $/ \mathrm{cm}^{2}$ ), cells were transfected with the indicated plasmids using BioT Transfection agent according to the manufacturer's recommendations. Further description of transfection and DOX treatments is available in the Supplemental Material. Mouse Embryonic Fibroblasts (MEFs) wild-type and SIRT1 -/- were cultured in $25 \mathrm{mM}$ glucose DMEM supplemented with $10 \%$ FBS and 1\% Penicillin/Streptomycin and under standard-cell culture conditions. These MEFs were previously generated from wild-type or homozygous SIRT1 -/- sibling mice (Nakahata et al. 2008). Details on cell treatment are given in the Supplemental Material.

\section{Sulforhodamine B assay}

HEK 293 were seeded in 48 well-plates at a concentration of $2.5 \times 10^{4} \mathrm{cells} / \mathrm{cm}^{2}$. At the end of DOX treatment $(0.05,0.5$, and $1 \mu \mathrm{M} ; 20 \mathrm{~h}$ ), cells were fixed overnight and then incubated with $200 \mu \mathrm{L} 0.05 \%$ (w/v) SRB solution. WT MEFs were seeded at $1.1 \times 10^{4}$ cells $/ \mathrm{cm}^{2}$ and exposed to dexamethasone (DEX) for $1 \mathrm{~h}$ followed by DOX (up to $1 \mu \mathrm{M}$ ) incubation for $12 \mathrm{~h}$, after which cells were fixed or kept in culture for $30 \mathrm{~h}$ in DOX-free medium before fixation. Dye bound to cellular proteins was extracted with $1 \mathrm{~mL}$ Tris $(10 \mathrm{mM}, \mathrm{pH}$ 10) and absorbance was read at $530 \mathrm{~nm}$ (Silva et al. 2016).

\section{RNA extraction}

Total RNA was extracted from MEF cells and frozen leftventricles with TRIzol reagent, as described in the Supplemental Material.

\section{CDNA preparation and quantitative real-time PCR}

For gene expression-analysis by qRT-PCR, $1 \mu \mathrm{g}$ mRNA was retrotranscribed into cDNA using iScript RT supermix according to manufacturer's instructions. Further details are available in Supplemental Material.

\section{Protein extraction}

Cells and tissues were lysed in RIPA buffer. Briefly, $1 \mathrm{~mL}$ of RIPA supplemented with inhibitors (0.5 mM PMSF, 1 $\mu \mathrm{l} / \mathrm{ml}$ protease inhibitor cocktail, $20 \mathrm{mM} \mathrm{NaF}, 10 \mathrm{mM} \mathrm{NAM}$, $330 \mathrm{nM}$ TSA, and $0.5 \%$ DOC) was added either directly to the cell culture, after a first wash with PBS, or to $\sim 20 \mathrm{mg}$ ventricular tissue. Cell lysates were then transferred to tubes and placed at $4{ }^{\circ} \mathrm{C}$, rocking for $30 \mathrm{~min}$ and vortexed every $5 \mathrm{~min}$. Lysates were then sonicated $3 \times 10 \mathrm{~s}$ and centrifuged at $18,000 \times g$ for $20 \mathrm{~min}\left(4^{\circ} \mathrm{C}\right)$ and the pellet was discarded. Protein content was measured using BCA assay and using bovine serum albumin as standard. Protein was kept at $-80^{\circ} \mathrm{C}$ until use.

\section{Immunoprecipitation}

Protein extracts from HEK 293 cells co-transfected with flag-SIRT1, myc-BMAL1 and myc-CLOCK were immunoprecipitated with an anti-myc antibody, as described in Supplemental Material. Acetylated BMAL1 levels in the presence or absence of DOX were assessed by Western Blotting.

\section{Western Blotting}

Protein semi-quantification was performed by western blotting, according to the protocol described in the Supplemental Material.

\section{RNA sequencing}

RNA was extracted from ZT 9- and ZT 21 left ventricles of 3 animals per group (group 1: SAL ZT 9; group 2: SAL ZT 21; group 3: DOX ZT 9; group 4: DOX ZT 21), using the standard PureZOL protocol, as described in the Supplemental Material.

\section{Histological staining}

Mice hearts were quickly harvested, rinsed with PBS, embedded in cryomatrix and frozen in liquid nitrogen. Later, frozen hearts were sliced $10 \mu \mathrm{m}$ thick in a Leica CM1950 cryostat at $-20{ }^{\circ} \mathrm{C}$. Sections were stored at $-80^{\circ} \mathrm{C}$. Histological sections were processed as detailed in Supplemental Material.

\section{Results}

\section{Juvenile mouse model of persistent DOX-induced cardiac dysfunction}

\section{Animal mass and indicators of cardiac injury}

Four-week old juvenile mice received injections of saline or DOX during 4 consecutive weeks. Six weeks after the final injection, animals were sacrificed and hearts collected. Although both groups gained weight during the period of study, DOX sub-chronic treatment caused a significant slower-weight gain over time, as seen by the differences of 
body mass values between groups (Table 1; Fig. 1a). While saline animals presented a $\sim$ twofold increase in body mass from the beginning to the end of the experiment, mice in the DOX group displayed an increase of only $\sim 1.7$-fold. An $11 \%$ reduction of heart mass was observed at the end of the experiment in DOX-injected animals compared to controls (Table 1; Fig. 1b). However, heart mass over body mass ratio showed a significant increase in DOX-treated animals (1.13fold) (Table 1; Fig. 1c), mostly resulting from the lower body weight. Hearts from saline- and DOX animals were harvested and processed for histochemical analysis. Sections stained with HE appeared morphologically normal with no obvious signs of damage, even though gross observations suggested mild fibrotic changes (Fig. 1d). The analysis of the expression of the cardiac injury biomarkers, brain natriuretic peptide (BNP) and atrial natriuretic peptide (ANP), showed increased transcription levels in DOX-treated animals (Fig. 1e, f). While ANP mRNA levels significantly increased 2.8-fold in DOX animals (Fig. 1e), no statistically relevant difference was observed in total BNP levels between saline- and DOX groups (1.4-fold difference) (Fig. 1f). Interestingly, BNP transcript levels exhibited a daily oscillatory profile, with DOX animals showing significantly increased BNP expression at ZT 21 (Fig. 1f).

\section{Persistent DOX effects on gene expression}

To explore whether the sub-chronic DOX early exposure leads to persistent alteration of gene expression, we investigated the circadian oscillations and total transcript levels of clock and metabolic genes by qRT-PCR (Fig. 2). Saline and DOX-treated mice were sacrificed every $6 \mathrm{~h}$ over the
Table 1 Body and heart mass profile of mice subjected to DOX sub-chronic protocol

\begin{tabular}{|c|c|c|c|c|c|c|c|c|}
\hline \multirow[t]{2}{*}{ Treatment } & \multicolumn{2}{|c|}{$\begin{array}{l}\text { Initial body mass } \\
(\mathrm{g})\end{array}$} & \multicolumn{2}{|c|}{ Final body mass (g) } & \multicolumn{2}{|c|}{ Heart mass } & \multicolumn{2}{|c|}{ HM:BM (×100) } \\
\hline & Mean & SEM & Mean & SEM & Mean & SEM & Mean & SEM \\
\hline Saline $(n=20)$ & 14.050 & 0.486 & 28.695 & 0.430 & 0.145 & 0.003 & 0.499 & 0.008 \\
\hline $\operatorname{DOX}(n=20)$ & 13.555 & 0.375 & $23.073 * * *$ & 0.447 & $0.129 * * *$ & 0.003 & $0.563 * * *$ & 0.013 \\
\hline
\end{tabular}

$H M: B M$ heart mass to body mass ratio, SEM standard error of the mean $* * * p<0.001$ vs saline group

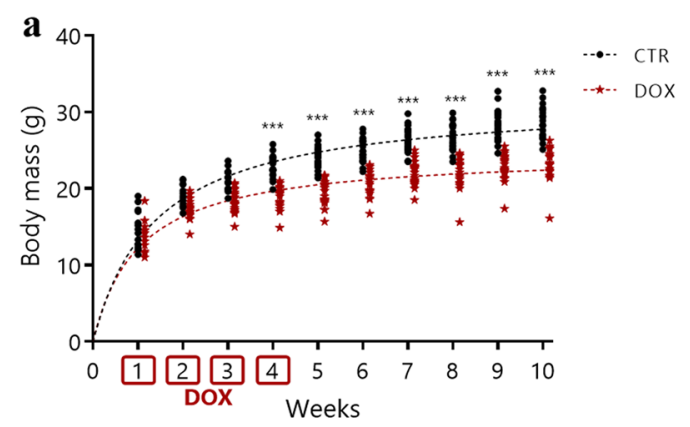

b

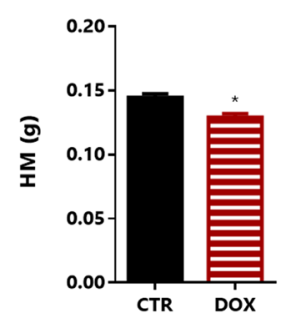

e

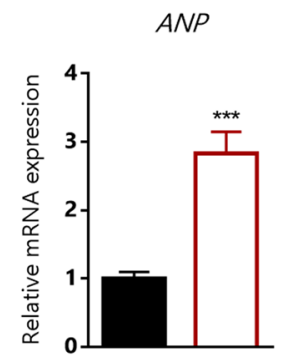

C

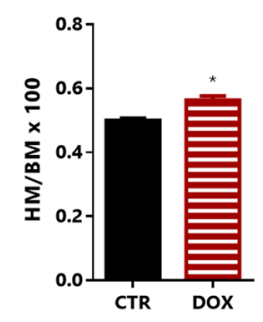

f

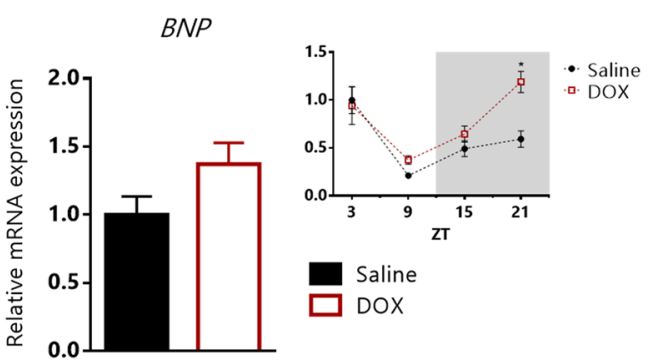

Fig. 1 Weight, histochemical- and transcriptional analysis of salineand DOX-injected young mice. a Mice body weight recorded along the 10-weeks experiment (four weeks of treatment plus 6 weeks of recovery). Lines represent the weight curve based on the means of each group over time. b Heart weight in grams and $\mathbf{c}$ heart-to-bodyweight ratio in saline- and DOX-injected animals 6 weeks after the end of treatment. d Representative images of heart sections stained with HE. Scale bar represents $100 \mu \mathrm{m}$. e Total $A N P$ and $\mathbf{f}$ total and circadian $B N P$ mRNA levels were assessed by qRT-PCR. Error bars indicate SEM. ${ }^{*} p<0.05, * * * p<0.001$ DOX vs saline. $n=20$ per group, $n=5$ per group and ZT (zeitgeber time, light-dark cycle) 

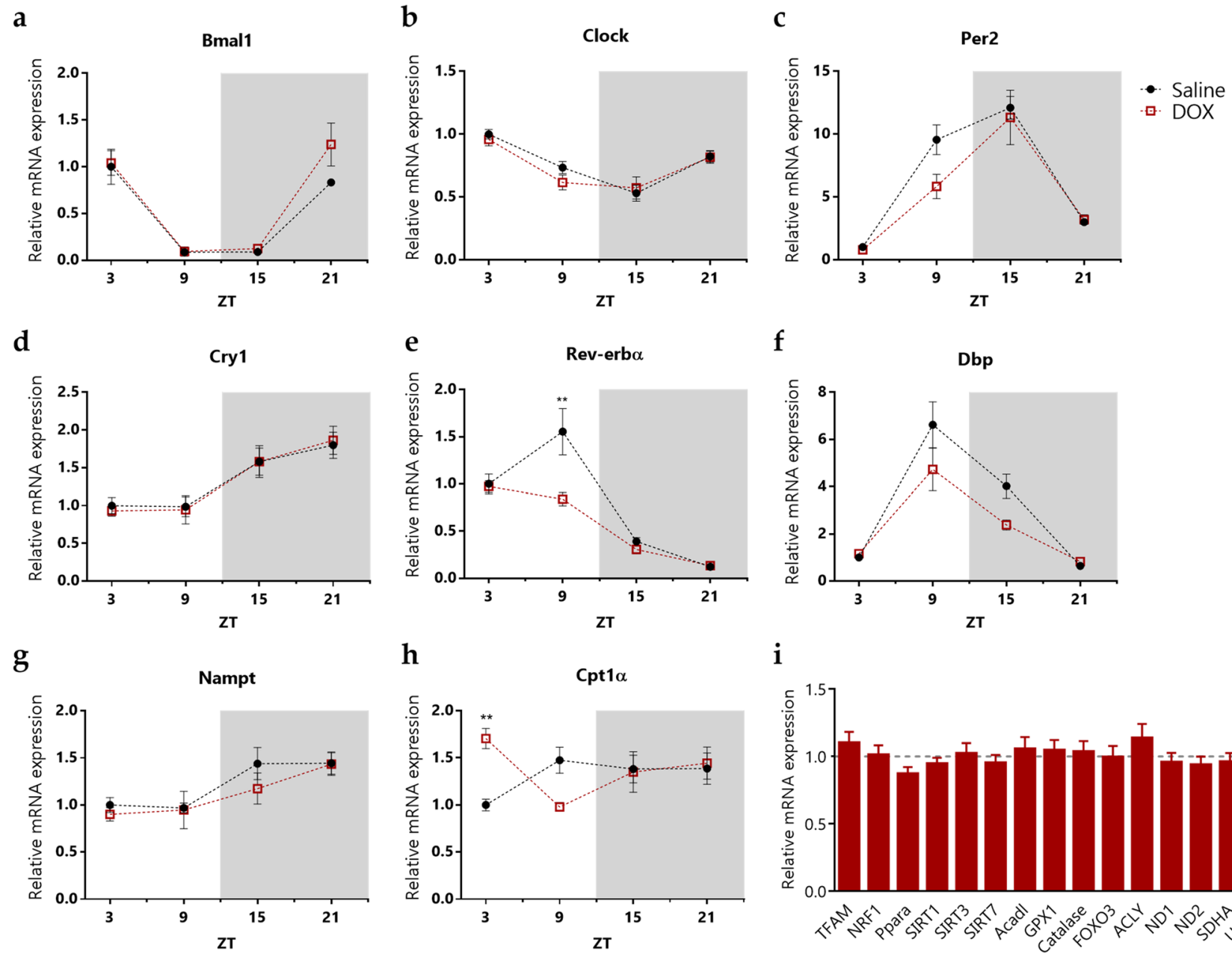

i

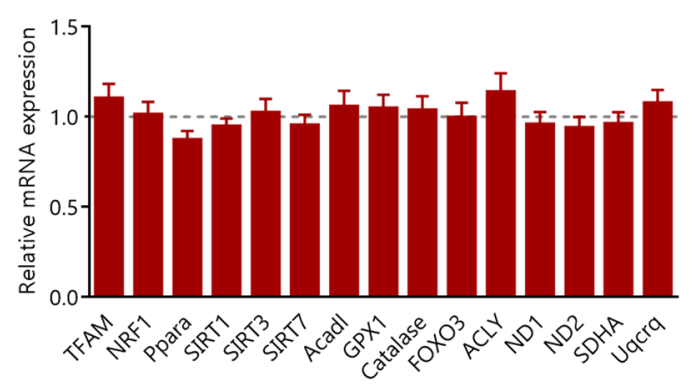

Fig. 2 Impact of DOX treatment on the expression of circadian molecular clock, metabolic- and mitochondrial-related genes in the heart. a-f Circadian expression levels of the core clock-genes (Bmall, Clock, Per2, Cry1, Rev-erb $\alpha, D b p)$, g Nampt and $\mathbf{h}$ Cpt1 $\alpha$ were deter- mined by qRT-PCR. I) Total mRNA levels of important metabolicand mitochondrial genes were assessed by qRT-PCR. Error bars indicate SEM. ${ }^{* *} p<0.01$ DOX vs saline. $n=20$ per group, $n=5$ per group and ZT (zeitgeber time, light-dark cycle) circadian cycle (ZT 3, 9, 15, 21) and left ventricles were subjected to gene expression-analysis. While expression of clock genes Bmall, Clock, Per2, Cryl and clock-controlled gene $D b p$ was virtually unaffected by the treatment (Fig. 2a-d, f), Rev-erb $\alpha$ gene expression showed a significant dampening at ZT 9 (Fig. 2e). Nampt and Cptl $\alpha$ (carnitine palmitoyl transferase 1 alpha) genes also showed an oscillatory expression pattern, as previously described (Filiano et al. 2013; Nakahata et al. 2009). While Nampt expression appeared unalteratered, DOX led to a Cptl $\alpha$ peak in expression at ZT 3 (Fig. $2 \mathrm{~g}, \mathrm{~h}$ ). The Cpt1 $\alpha$ enzyme is involved in long-chain fatty acids transport across the outer mitochondrial membrane and its availability is related with fatty acid oxidation capacity (Bonnefont et al. 2004). Considering the described effects of DOX on mitochondrial function and oxidative stress in the cardiac tissue, mRNA expression of genes belonging to mitochondrial biogenesis, electron transport chain and antioxidant pathways was analyzed, as well as the expression of Sirt1, Sirt3 and Sirt7 (Fig. 2i). The analyzed genes presented no significant total or rhythmic gene expression-alteration.

To better characterize the delayed effects of DOX on mice transcriptome, RNA sequencing was performed in 4 different groups of mice (saline ZT 9, saline ZT 21, DOX ZT 9 and DOX ZT 21) to unveil alterations on saline vs DOX animals and to detect changes on gene oscillation between those 2 time-points. Global transcriptome profiling identified 54 transcripts differentially expressed in DOX mice compared to the vehicle control (FDR $<0.05)$. From these 54 genes, only 5 were downregulated after DOX treatment $(\mathrm{Tmem} 150 \mathrm{c}$, Inmt, $P f k f b l$, Aldob and $P p l$ ) (Fig. 3a). The biological process most significantly enriched among the upregulated transcripts included innate immune response $\left(p<10^{-4}\right)$, indicative of inflammatory response. In this category, interferon regulatory 
a

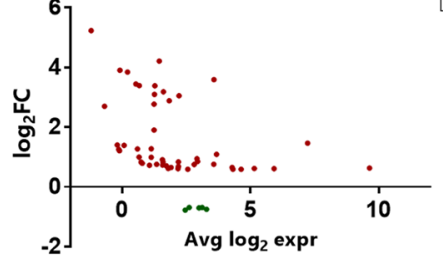

d

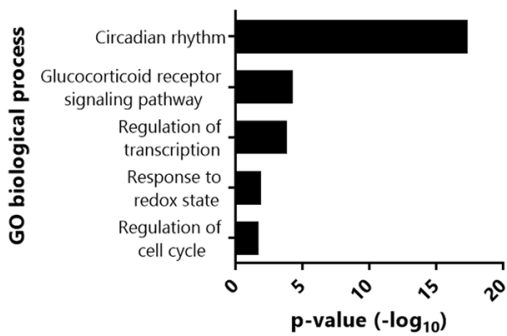

b

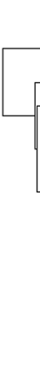

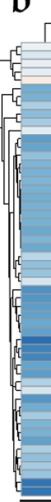

C

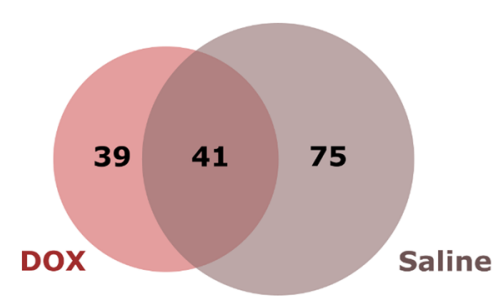

Fig. 3 RNA sequencing-analysis and identification of oscillatory transcripts upon DOX treatment. a MA plot of DOX-differentially expressed genes compared with vehicle-treated mice (red dots: overexpressed genes; green dots: under-expressed genes). $\log 2 \mathrm{FC}$ : $\log 2$ fold change; avg $\log 2$ exp: average $\log 2$ expression. b Gene expression-heatmap view of saline and DOX mice groups $(n=6)$. Each row represents a gene, and each column represents each of the 12 animals analyzed. c Venn diagram of detected oscillators between ZT 9 and ZT 21, for saline and DOX. d-f Enrichment analysis (gene ontology, biological process) of oscillating genes in both conditions $\mathbf{d}$, uniquely in salines $\mathbf{e}$ and uniquely in DOX-treated mice $\mathbf{f}$, represented as negative of $\log 10$ of $\mathrm{p}$-value after Bonferroni correction (colour figure online) factor 7 (Irf7), interferon-induced protein with tetratricopeptide repeats (Ifit1-3), toll-like receptor 12 (Tlr13), 2'-5' oligoadenylate synthetase $1 \mathrm{~A}($ Oas $1 \mathrm{a})$ or $2^{\prime}-5^{\prime}$ oligoadenylate synthetase-like 1 (Oasll) were overexpressed. Hierarchical clustering and heatmap analysis of the 6 replicates indicated the reproducible nature of the analysis and highlighted the transcriptional changes between the treatments (Fig. 3b). However, it was possible to observe variability between the 6 DOX animal patterns, possibly due to different individual recovery responses during the following period. To identify alterations on the oscillation patterns between ZT 9 and ZT 21 , a comparison of gene expression was performed between both ZT for the same condition (saline ZT 9 vs saline ZT 21, and DOX ZT 9 vs DOX ZT 21). While in the saline group 116 genes presented significant oscillation between both time-points, this number was lower for DOX-treated mice, with 80 genes oscillating (FDR $<0.05)$. Within these genes, 41 were commonly detected in both groups, while 39 and 75 were found to oscillate exclusively in DOX and saline groups, respectively (Fig. 3c). Gene ontology analysis of the commonly oscillating genes showed a strong enrichment for circadian rhythms, followed by circadian-related pathways, including regulation of glucocorticoid receptor signaling pathway, regulation of transcription, response to redox state and regulation of cell cycle (Fig. $3 \mathrm{~d}$ ), indicating that the peripheral core clock machinery was not affected by the treatment. Saline oscillators were enriched for biological processes including cell adhesion, regulation of MAPK cascade, response to organic substances, inflammatory response, regulation of blood vessel size and vasoconstriction or positive regulation of heart rate (Fig. 3e). On the other hand, the top DOX specific oscillating pathways included cytoskeleton organization, anterior/posterior pattern specification, regulation of membrane depolarization and ion transport (Fig. 3f). While differences in gene expression between 2 time-points is not sufficient to categorize a gene as circadian, several oscillating genes in the murine left ventricle were already described as circadian according to Circadian Expression Profiles Data Base (CircaDB, https://circadb.hogeneschl ab.org/). Among the differentially expressed genes, mRNA levels of some particular genes were confirmed by qRT-PCR using the same RNA samples used for RNA-sequencing 
analysis (Fig. 4). Prg4 and cytll loss of oscillation after DOX treatment was confirmed, even though not statistically significant $(n=3)$ (Fig. 4a, c). However, $p d k 4$, found to have increased oscillation in DOX mice, did not show this same pattern when analyzed by qRT-PCR (Fig. 4b). Interestingly, $c d k n l a$ (involved in cell cycle arrest and DNA damage response) and Irf7 (involved in immune system processes) mRNA analysis reinforced RNA sequencing-results as these were both shown to be overexpressed by 1.7-fold and 6.0fold, respectively, in DOX-treated animals in comparison to saline mice (Fig. 4d, e).

\section{SIRT1 levels and SIRT1-mediated oscillatory deacetylation}

A reduction in SIRT1 protein and mRNA levels in in vitro and in vivo models of DOX-induced cardiac injury was previously reported (Cui et al. 2017; Wang et al. 2017; Zhu et al. 2017). However, DOX effects on SIRT1 deacetylase activity have not been elucidated yet. SIRT1 interacts with a number of proteins, including PGC- $1 \alpha$ (Nemoto et al. 2005), LKB1 (Wang et al. 2017), p53 (Cheng et al. 2003), Per2, H3 and BMAL1 (Masri and Sassone-Corsi 2014). We investigated whether the early DOX treatment would mediate changes in the acetylation levels of two SIRT1 targets, H3K9 and BMAL1, both crucial in the maintenance of circadian processes. Western blotting results in saline and DOX samples collected at ZT 9 and ZT 21 showed that the acetylation levels of H3K9 were altered in response to DOX treatment (Fig. 5a, b). While in saline samples the levels of $\mathrm{H} 3 \mathrm{~K} 9$ acetylation were similar for both time-points, DOX-induced significant changes between ZT 9 and ZT 21, with higher acetylation at ZT 21 (Fig. 5b). Circadian acetylation of BMAL1 at Lys538 was significantly inverted by DOX treatment when compared to saline controls (Fig. 5a, d). Importantly, BMAL1 protein levels presented different patterns in both groups (Fig. 5a, c). SIRT1 levels did not change between conditions for the respective time-points, although a significant difference was observed in DOX ZT 21 as compared with saline ZT 9 (Fig. 5e).

\section{In vitro effects of DOX on the circadian expression and SIRT1-mediated acetylation}

\section{DOX effects on the circadian clock in Mouse Embryonic Fibroblasts}

To obtain mechanistical insights to the effects of DOX treatment on the circadian clock, MEFs from WT mice were incubated with DOX for mRNA expression and a

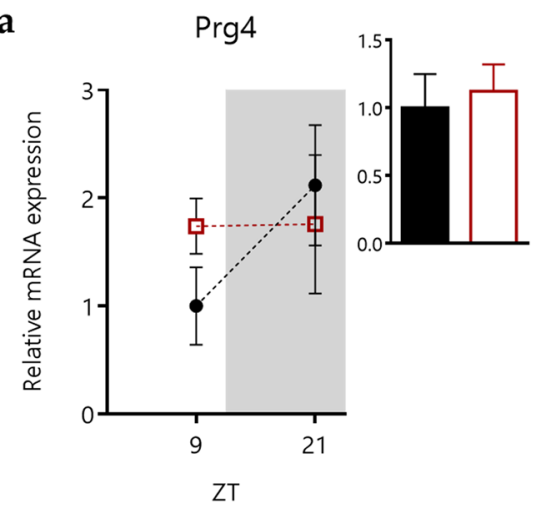

d

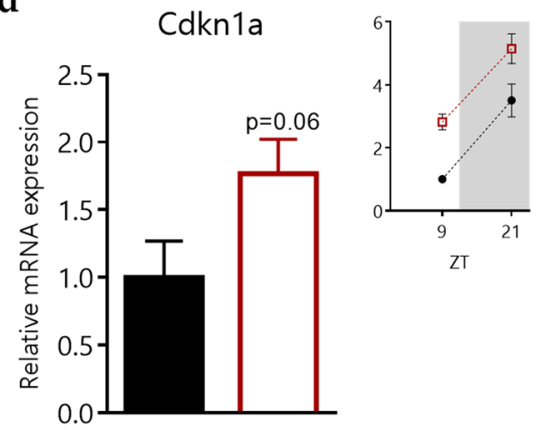

b

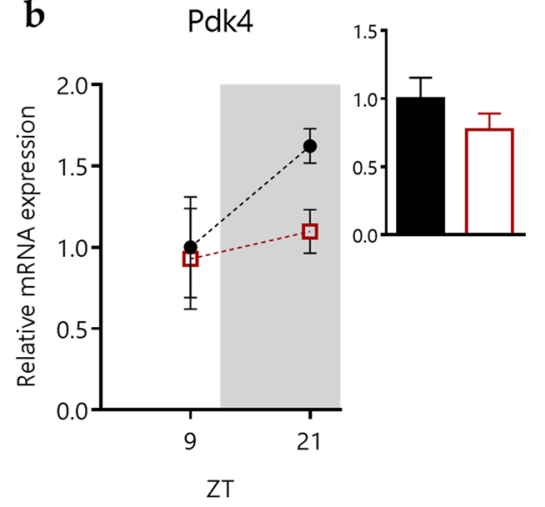

e

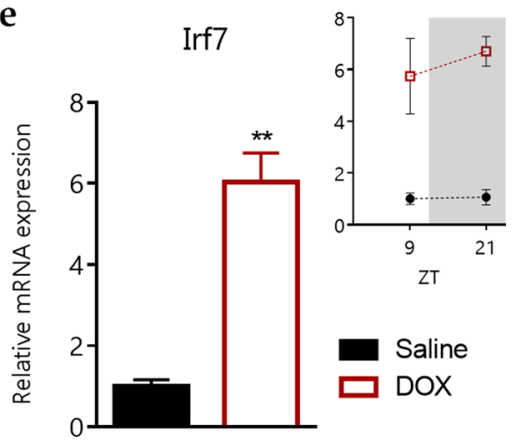

c

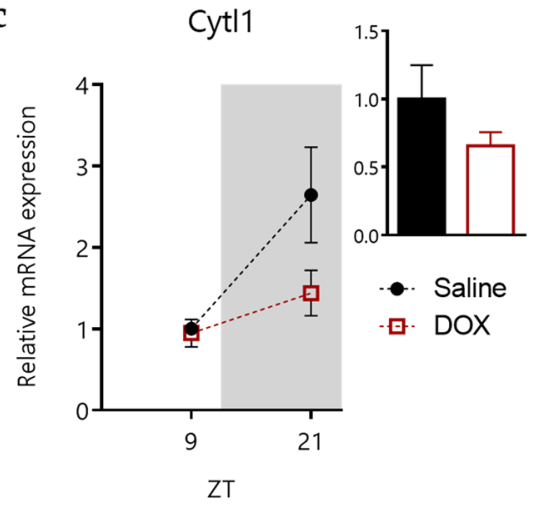

Fig. 4 Gene expression-profiles in saline- and DOX mouse-heart. Total- and oscillating (ZT 9 and ZT 21) mRNA levels of Prg4 (a), Pdk4 (b), Cytll (c), Cdknla (d), and Irf7 (e), determined by qRT-
PCR. Error bars indicate SEM. ${ }^{*} p<0.01$ DOX vs saline. $n=6$ per group, $n=3$ per group and ZT (zeitgeber time, light-dark cycle) 
Fig. 5 Western blotting analysis of SIRT1- and SIRT1 deacetylation targets in mouse hearts. a Total protein expression and acetylation levels of $\mathrm{H} 3 \mathrm{~K} 9$ and BMAL1 at ZT 9 and ZT 21. bd Oscillatory levels of the ratio acetylated $\mathrm{H} 3 \mathrm{~K} 9 /$ total $\mathrm{H} 3 \mathrm{~K} 9$ (b), total BMAL1 (c), and the ratio acetylated BMAL1/total BMAL1 (d). e Total SIRT1 protein levels. Error bars indicate SEM. * $p<0.05$ ZT 21 vs ZT 9; \#p<0.05 DOX vs saline at ZT 21; $\Phi p<0.05$ DOX ZT 21 vs CTR ZT 9. $n=3$ per group and ZT a

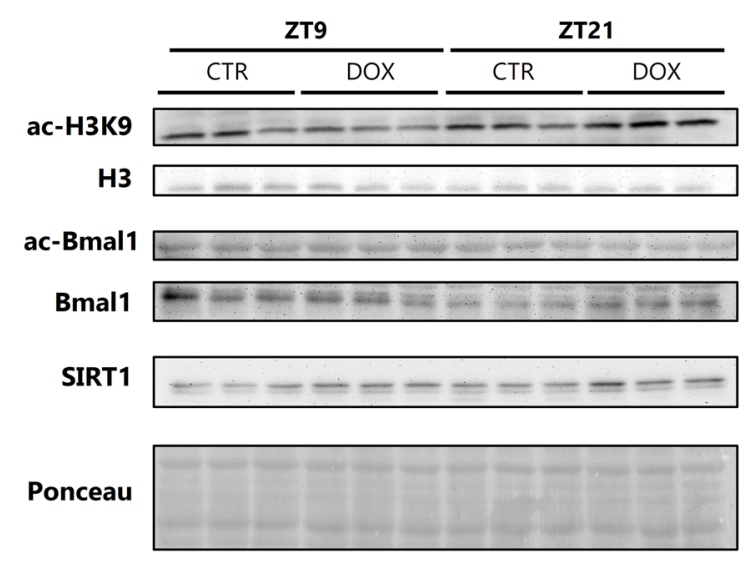

e

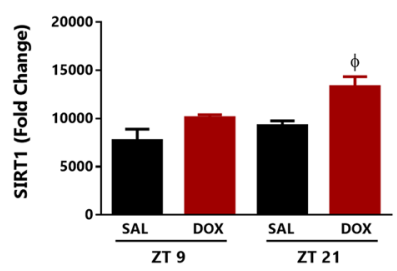

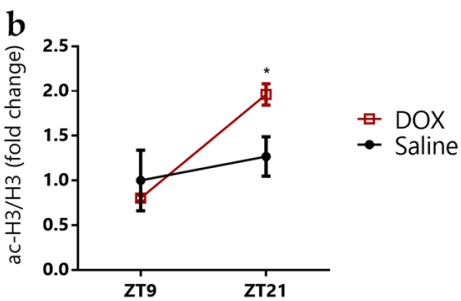

c
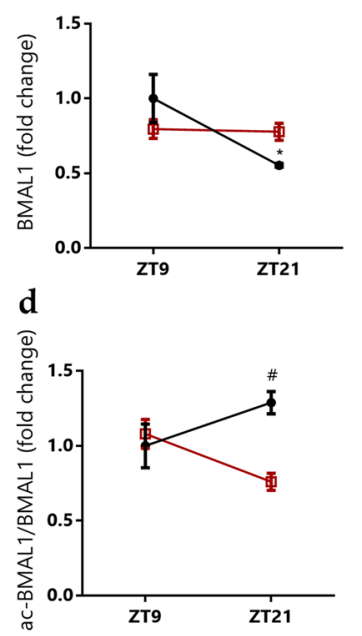

protein analysis. The corticosteroid DEX is commonly used to synchronize the circadian clock in cultured cells (Balsalobre et al. 2000). Circadian-gene expression in cultured cells was proven to be induced by serum shock (Balsalobre et al. 1998) and by DEX (Balsalobre et al. 2000), which was shown to induce Perl expression. Given the cytotoxicity of DOX and considering that gene expressionanalysis should be performed before triggering severe-cell death events, SRB was used to assess the suitable DOX concentration to be used in the assay. After the $1 \mathrm{~h}$ preincubation with DEX (Supplemental Figure 3), cells were incubated with DOX (10 nM-1 $\mu \mathrm{M})$ for $12 \mathrm{~h}$. No effects were observed on cell mass after $12 \mathrm{~h}$ incubation (Fig. 6a). However, after $30 \mathrm{~h}$ of recovery time in drug-free medium, a very significant decrease in cell mass in DOX-treated cells was observed, possibly by affecting cell proliferation (Fig. 6a). Although significantly decreasing cell mass, $50 \mathrm{nM}$ DOX was chosen for the following assays since it seemed an adequate concentration to affect cell function while still allowing cell proliferation during the $30 \mathrm{~h}$ period. DEX incubated alone or in combination with DOX did not alter cell viability. Cells were initially collected after DOX incubation period, which means $12 \mathrm{~h}$ after DEX synchronization, and then collected every $6 \mathrm{~h}$ during a $30 \mathrm{~h}$ period. Gene expression-analysis of core clock and metabolic genes was performed for all time-points (Figs. 6, 7). Overall, the circadian patterns confirmed the efficacy of DEX synchronization. From the clock mRNA transcripts, including Bmal1, Dbp, Rev-erbo, Cry1, Per1, Per2, and $R O R \alpha$, only $D b p$ and $R e v-e r b \alpha$ presented an increased peak of expression at CT 24 compared with the respective controls, whereas Per 2 expression showed a prolonged peak in mRNA levels that instead of declining at CT 30 continued at maximal levels (Fig. 6b-h). Since no differences in Bmall expression were observed after treatment, the circadian- and total BMAL1 protein levels were confirmed by western blotting (Fig. 6i, j). Neither the total BMAL1 protein levels (DOX 0.1 and $0.5 \mu \mathrm{M}$ ) nor the differential protein expression over time (DOX $0.1 \mu \mathrm{M})$ were affected by DOX treatment. Interestingly, we observed multiple alterations in gene expression of metabolic genes (Fig. 7). The more notable were the upregulations of $C p t 1 \alpha$ and Ppar $\alpha$, both related with fatty acid metabolism (Fig. 7c, i). Additionally, Acadl suffered a phase-shift, Uqcrq was up-regulated at CT 24 and TFAM was overall under-expressed with a significant alteration at CT 36.

\section{DOX effects on SIRT1 activity and total acetylation}

To test the in vitro ability of SIRT1 to deacetylate BMAL1 after DOX treatment, expression vectors encoding flagtagged murine SIRT1, and myc-tagged murine BMAL1 and CLOCK were co-transfected into HEK 293 cells, as these cells are good transfection hosts (Fig. 8). DOX (0.05, 0.5 and $1 \mu \mathrm{M})$ cytotoxicity was first screened on HEK 293 
a
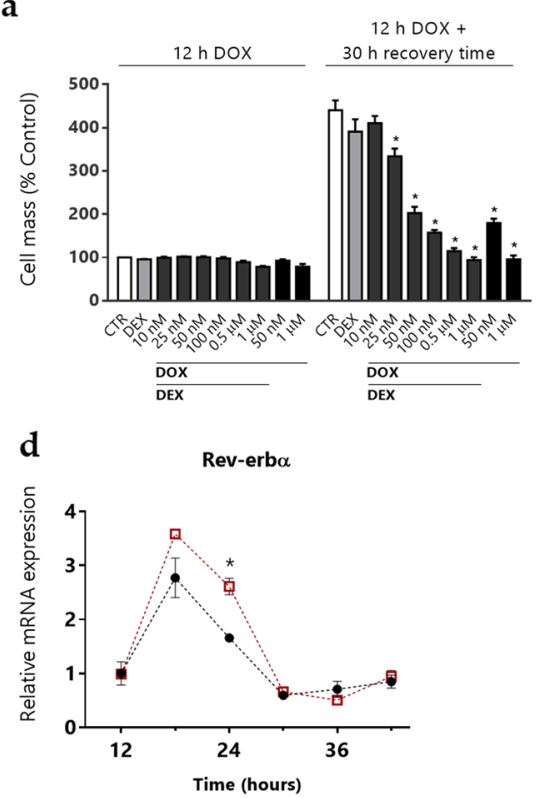

g

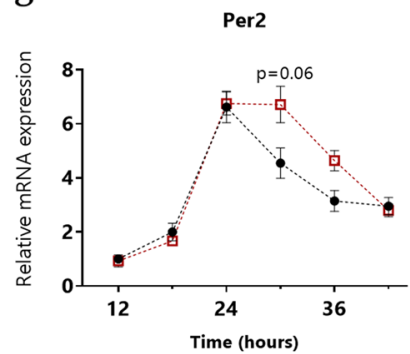

J
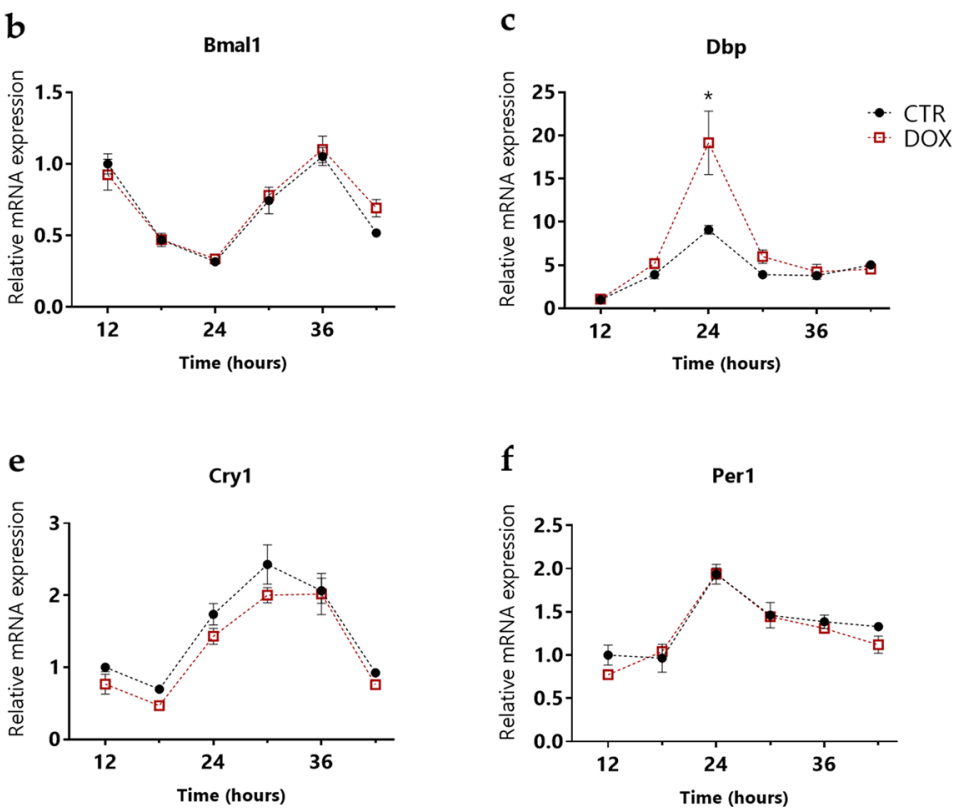

h

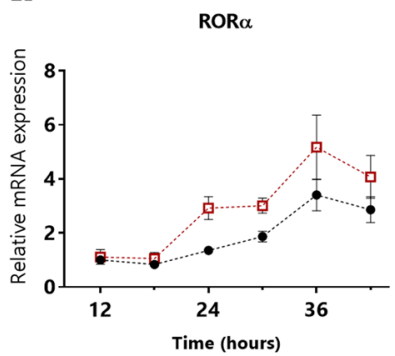

f Per1

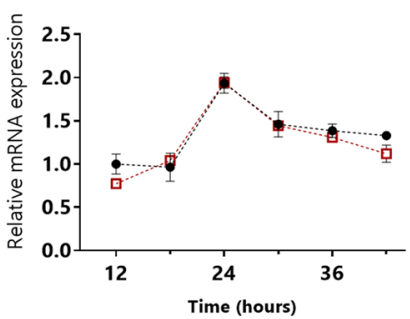

i
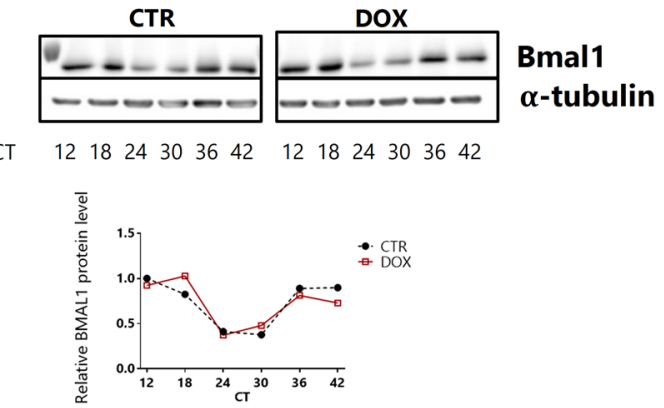

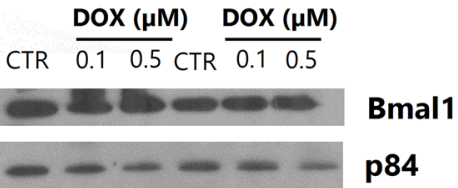

Fig. 6 Impact of DOX treatment on WT MEFs circadian molecular clock. a SRB analysis of MEFs synchronized with DEX (dexamethasone; $100 \mathrm{nM})$ and treated with DOX $(10 \mathrm{nM}-1 \mu \mathrm{M})$ for $12 \mathrm{~h}$. Results express protein content right after the treatment and after $30 \mathrm{~h}$ of recovery time in DOX-free medium. $n=3$ per condition. b-h Circadian expression levels of Bmall (b), Dbp (c), Rev-erb $\alpha$ (d), Cryl,

by SRB. Only $1 \mu \mathrm{M}$ DOX (20 h exposure) significantly decreased HEK 293 cell mass (Fig. 8a). BMAL1 acetylation levels were measured after immunoprecipitation with anti-myc, and further western blotting with acetyl-Bmal1 antibody (Fig. 8b). To measure acetylated levels of BMAL1, the acetyltransferase CLOCK was used to counteract SIRT1 deacetylase activity. The efficiency of the transfection was confirmed by western blotting with anti-myc and anti-flag antibodies and comparison with the input signal. SIRT1transfected cells presented lower levels of acetyl-BMAL1, and DOX dose-dependently reduced BMAL1 acetylation
$\operatorname{Per} 1$ (f), $\operatorname{Per} 2(\mathbf{g})$, and $R O R \alpha(\mathbf{h})$ was determined by qRT-PCR. $\mathrm{n}=3$ per group and CT (circadian-time). $\mathbf{i}-\mathbf{j}$ BMAL1 protein content was determined by western blotting. i BMAL1 oscillatory protein of control and 0.1 $\mu \mathrm{M}$ DOX-treated MEFs. $\mathbf{j}$ Total BMAL1 protein of control and cells treated with 0.1 and $0.5 \mu \mathrm{M}$ DOX, assayed in duplicate. Error bars indicate SEM. * $p<0.05$ DOX vs control

compared with non-treated cells. To confirm these results, WT and SIRT $1^{-1-}$ MEFs were treated with DOX (1 and $2 \mu \mathrm{M})$ and the acetylation levels of BMAL1 and acetyl-CoA synthase 1 (AceCS1), another SIRT1 target (Sahar et al. 2014), were measured (Supplemental Figure 4). Again, both DOX treatments led to a reduction of BMAL1 acetylation compared with control cells. Decreased acetyl- BMAL1 levels were also observed in DOX-treated SIRT1 ${ }^{-1-}$ cells, but band-intensities were significantly higher than in WT MEFs. Thus, even though SIRT1-mediated BMAL1 deacetylation may be affected by DOX, it does not seem to be 
a

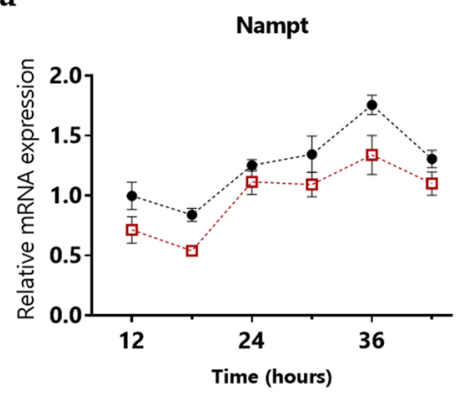

d

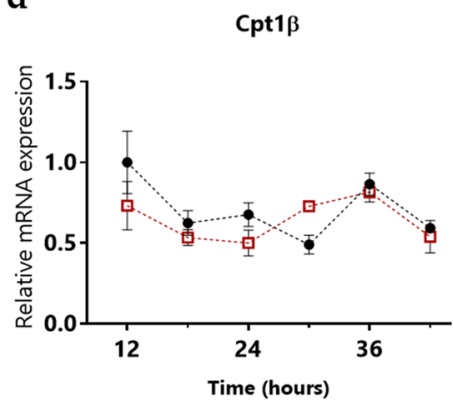

g

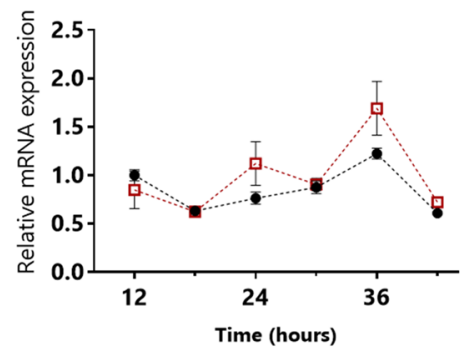

j

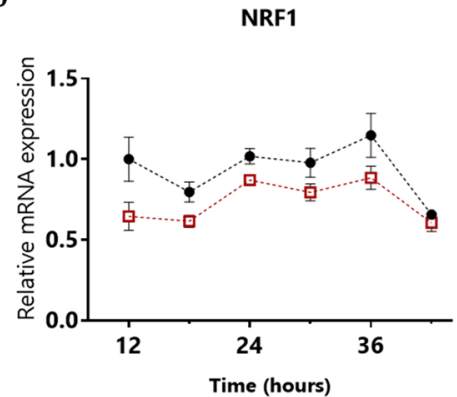

b

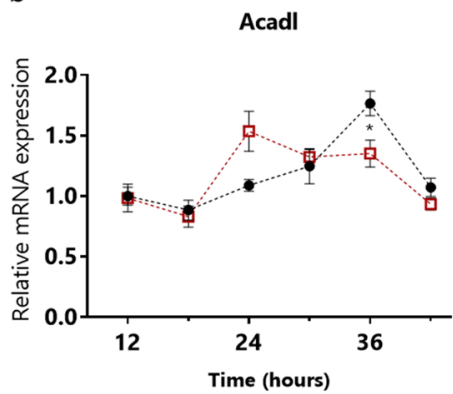

e

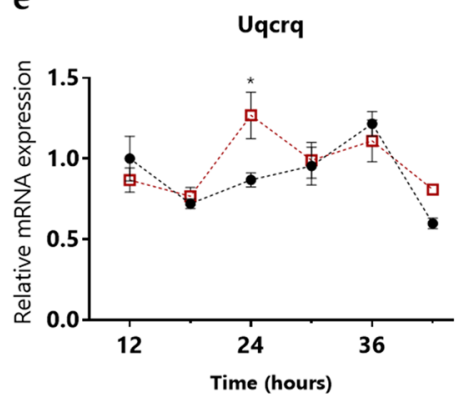

$\mathbf{h}$

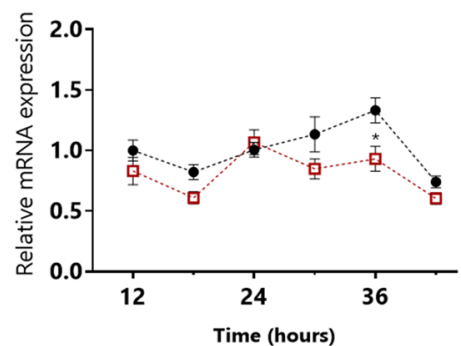

c

Cpt1 $1 \alpha$

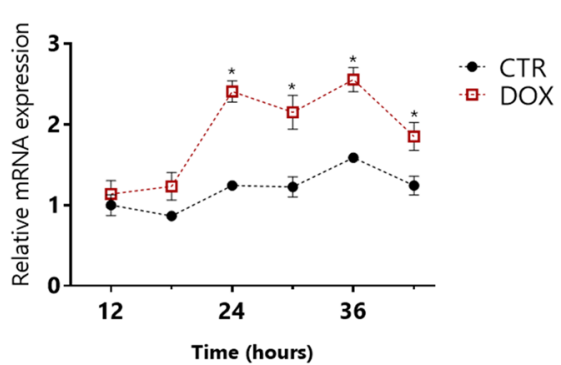

f

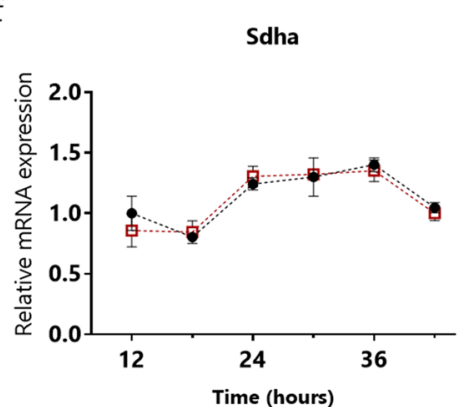

i

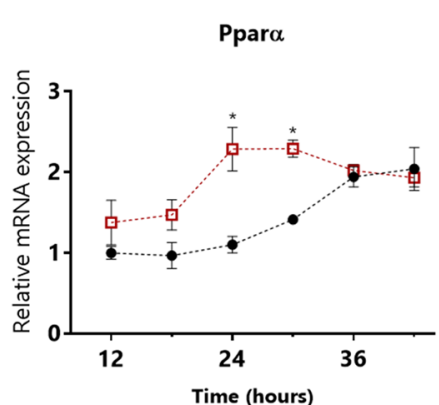

Fig. 7 DOX effects on gene expression of metabolic and mitochondrial proteins in WT MEFs. a-j Circadian-gene expression of metabolic genes over the circadian-time: Nampt (a), Acadl (b), Cptl $\alpha$

the only mechanism affecting the acetylation levels. Other sirtuins may be involved as well, since the Ex527 inhibitor, used at a concentration $(50 \mu \mathrm{M})$ is not totally selective for SIRT1 (Gertz et al. 2013). Ex527 treatment considerably increased levels of acetyl-Bmal1 intensity in both WT and $\mathrm{SIRT}^{-/-}$cells. Similarly, acetyl-AceCS1 decreased with

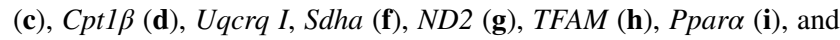
$N R F 1$ (j). Error bars indicate SEM. ${ }^{*} p<0.05$ DOX vs control. $n=5$ per group and CT (circadian-time)

DOX treatment in both cell lines, suggesting that SIRT1 activity may not be the only reason for the reduction of AceCS1 acetylation. Interestingly, BMAL1 phosphorylation state (detected as upper- and lower bands in Bmal1 western blotting) seemed to be altered with DOX exposure. Globallysine acetylation was not dramatically impacted by DOX, 
Fig. 8 BMAL1 acetylation levels in HEK 293 cells. a SRB analysis of HEK 293 cells treated with DOX $(0.05,0.5$ and $1 \mu \mathrm{M}$ ) for $20 \mathrm{~h}$. Results express protein content right after the treatment. $n=4$ per condition. b HEK 293 were co-transfected with expression vectors (flagSIRT1, myc-BMAL1, mycCLOCK) and treated with DOX $(0,0.05,0.5,1 \mu \mathrm{M})$. The protein extracts were immunoprecipitated with an anti-myc antibody and the levels of BMAL1 acetylated were assessed. IP immunoprecipitation, $I B$ immunoblotting, $\operatorname{Ig} G$ immunoglobulin G. Error bars indicate SEM. $* p<0.05$ DOX vs control

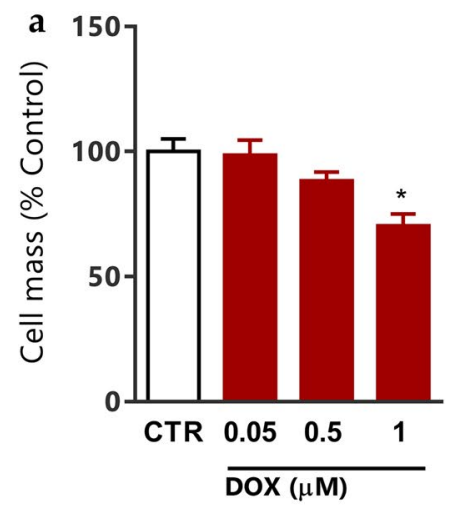

b

Flag-SIRT1

Myc-Bmal1

Myc-Clock

IP: anti-myc

IB: anti-ac-Bmal1

anti-flag

anti-myc

Clock >

Bmal1 >

Input:

anti-ac-Bmal1

anti-flag

anti-myc

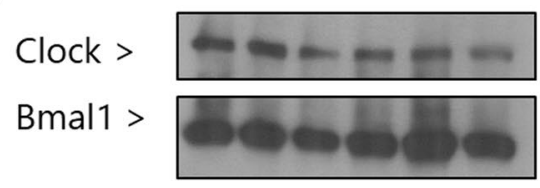

even though some particular bands were more intense after the treatment (Supplemental Fig. 4b). Similarly, SIRT1 ablation increased some band-intensities but did not cause major alterations in the overall profile.

\section{Discussion}

Multiple lines of evidence support the role of disrupted internal clock in the development of a number of pathologies (Bechtold et al. 2010). We believe that the multiplicity of perturbed pathways induced by DOX, which causes mitochondrial injury and DNA damage response, may interfere with cellular energy state and subsequently unbalance the circadian rhythms of the heart. DOX effects on the cardiovascular system are particularly relevant for late onset chronic manifestations, since cardiotoxicity can be developed as late as 15 years after treatment completion and most of the times it is difficult to keep track of children's health trajectories for so long. In this sense, it is important to clarify the impact of DOX in young hearts to understand how to manage preventive approaches. In this study, we investigated whether a sub-chronic DOX regimen in juvenile mice would interfere with the normal transcriptional oscillation and circadian-related acetylation patterns observed in the murine hearts 6 -weeks after finishing the treatment.
Further assays in MEFs and HEK 293 were performed to obtain deeper mechanistical insights.

The cumulative administration dose of $20 \mathrm{mg} / \mathrm{kg}$ DOX in juvenile mice induced a decrease in body-weight gain during the initial weeks, during DOX treatment, but also during the following recovery time, never reaching the values of the control group. Moreover, at the end of the experimental design, heart weight in DOX group was lower compared with saline controls, while the ratio heart/ body weight, an index of cardiac hypertrophy, was higher in DOX animals. These persistent phenomena have been reported by many others (Ghibu et al. 2012; Richard et al. 2011; Sacco et al. 2003). It was previously proposed that reduced heart weight results from cardiomyocyte loss by cell death processes, whereas the loss of body mass may be a consequence of decreased appetite and food consumption (Ghibu et al. 2012; Richard et al. 2011; Zhu et al. 2008). Although other experiments should have been performed to confirm the increased-myocardial collagen deposition in DOX-treated animals, HE staining suggested an increase in fibroblast number, as previously reported (O'Connell et al. 2017; Zhu et al. 2008). Other indicators of cardiac injury included the higher mRNA levels of cardiac ANP and BNP. Both natriuretic peptides are mainly synthesized in the heart and increased plasma ANP and BNP concentrations are useful predictive markers of heart failure (Langenickel et al. 2000; Takei et al. 2011). Functionally, ANP and BNP 
possess diuretic, natriuretic, and vasodilatory properties (Del Ry et al. 2014), and up-regulation of $A N P$ and $B N P$ have previously been reported in murine models of DOX-induced cardiotoxicity (Piotrowska et al. 2017; Yuan et al. 2018) and in pediatric patients (Ekstein et al. 2007; Lipshultz et al. 2012). Overall, the above results allow to conclude that the designed protocol was successful in establishing a juvenile model of DOX-induced cardiotoxicity with persistent repercussions later in life.

To address the impact of DOX exposure on the cardiac circadian expression, mice from both groups (saline and DOX) were sacrificed at 4 different times of the day, two during the light phase and the other during the dark phase. Gene expression-analysis by qRT-PCR revealed no major alterations on the master clock. From the 6 circadian genes analyzed, only Rev-erb $\alpha$ was differently expressed at ZT 9. Rev-erb $\alpha$ works as a repressor of BMAL1 transcription upon binding to the RORE region located in Bmall promoter region (Buhr and Takahashi 2013). Additionally, Rev-erb $\alpha$ also regulates the expression of other metabolic genes, coordinating the circadian rhythm and metabolism (Cho et al. 2012). The stabilization of Rev-erbo protein seems to directly affect mitochondria by enhancing their respiration and antioxidant defenses (Sengupta et al. 2016), whereas conditions of oxidative stress and inflammation modulate Rev-erb $\alpha$ transcription (Yang et al. 2014). All the other metabolic and mitochondrial-related genes, with the exception of $\operatorname{Cptl} \alpha$, also showed no differences in circadian and total expression compared with the respective controls. Thus, at least for this panel of genes, the recovery time given to the animals after the completion of the treatment seemed to rebalance the normal mRNA levels. To have a global overview of the transcriptional alterations caused by DOX, and considering that previous studies confirmed persistent alteration in gene expression-profiles (Berthiaume and Wallace 2007), we next performed a deep sequencing approach. Regardless of the ZT, DOX treatment did not modulate metabolic pathways, including glycolysis and fatty acid metabolism, as reported by others (Berthiaume and Wallace 2007), but instead resulted in the up-regulation of genes involved in the inflammatory response, including Irf7 and Ifit I-3. The family of interferon regulatory factors, to which IRF7 belongs, are known to be involved in host defending mechanisms including response to viral infection and DNA-damaging agents. IRF7 has also been associated with TNF-related apoptosis-inducing ligands and extrinsicapoptotic pathway (Huang et al. 2009). In agreement with our results, IRF7 was previously shown to be activated by several DNA-damaging chemotherapeutic agents including DOX (Kim et al. 2000). DOX induces IRF7 phosphorylation and translocation to the nucleus where it works as a transcription factor and mediator of DNA damage-signaling pathways (Kim et al. 2000). These regulatory factors are also implicated in cell cycle arrest and apoptosis. It is not also surprising that $c d k n 1 a$ (encoding $\mathrm{p} 21$ ) was also up-regulated in DOX animals. p21 is a cyclin-dependent kinase inhibitor that can interact and inactivate various cyclin-dependent kinases that control cell cycle phase transitions, resulting in cell cycle arrest usually to prevent the accumulation of mutations or to allow the function of DNA repair machinery. p21 up-regulation in response to DOX treatment was reported in several other studies (Lupertz et al. 2010; Maejima et al. 2008; Siu et al. 1999; Terrand et al. 2011).

Circadian homeostasis is crucial for normal body physiology. While some extent of plasticity can be achieved under somewhat stressing conditions, extreme situations can contribute to the misalignment of normal rhythmicity. Here we chose $2 \mathrm{ZT}, 12 \mathrm{~h}$ apart, to analyze total RNA expression and daily variation to identify possible alterations in the oscillatory expression patterns. We observed that the treatment did not alter the expression of the core circadian components but contributed to changes in the oscillation of genes participating in important cell functions, with emphasis to cell adhesion (stopped oscillating with DOX) and cytoskeleton organization (started oscillating with DOX). Importantly, these results refer to mRNA levels between ZT9 and ZT21, which means that no full conclusions can be taken from the overall circadian behavior. Yet, it is possible to conclude that the cardiac damage caused by DOX significantly affects the mRNA rhythmicity in the heart, flattening or accentuating the expression levels in the analyzed ZTs. Similarly, our results using MEFs as an in vitro model confirmed the effect on multiple cyclic gene expression-profiles. Obviously, the effects on this model were more evident as compared with the murine model, not only because of the lack of complexity of the cell model but also because of the differences between an acute treatment and a sub-chronic treatment followed by recovery.

BMAL1 deacetylation mediated by SIRT1 is required for the regulation of circadian transcription, whereas $\mathrm{H} 3 \mathrm{~K} 9$ acetylation and deacetylation cycles promote rhythmic induction of gene activation and gene silencing (Masri and Sassone-Corsi 2014). SIRT1, in turn, functions as a metabolic sensor, because of its dependency on the $\mathrm{NAD}^{+} / \mathrm{NADH}$ ratio, helping the cell to respond to stressing conditions. Still, when examining SIRT1 protein levels and the acetylation of H3K9 and BMAL1, we found evidence for altered acetylation patterns and possibly acetylation-related activity in the mouse. We have focused on SIRT1-mediated acetylation because of its role in regulating redox state, metabolism, and the circadian regulation (Masri and SassoneCorsi 2014). SIRT1 targets, include the circadian repressor PER2, whose deacetylation promotes PER2 degradation, and BMAL1, that requires rhythmic acetylation to recruit CRY1 to CLOCK-BMAL1 complex and therefore promote the activation and repression of circadian transcription (Asher et al. 
2008; Hirayama et al. 2007). Also, several reports described the benefits of SIRT1 on ameliorating DOX side-effects (Cui et al. 2017; Liu et al. 2016), and others observed reduced SIRT1 levels in response to DOX treatment (Cheung et al. 2015; Cui et al. 2017; Yuan et al. 2018). Corroborating the in vivo observations, both MEFs and HEK 293 confirmed the decreased acetylated states of BMAL1 and AceCS1. The latter participates in the biosynthesis of acetyl-CoA, using acetate as substrate, and its cyclic acetylation mediated by SIRT1 contributes for the rhythmicity of acetyl-CoA cellular levels (Hallows et al. 2006; Sahar et al. 2014). Since AceCS1 deacetylation is required for AceCS1 activation, we speculate that DOX may impact the nucleocytosolic acetyl-CoA pool that is used for de novo synthesis of fatty acids or histone acetylation, which would be interesting to explore further. Additionally, SIRT3 was reported to deacetylate and activate the mitochondrial AceCS2, and given the mitochondrial-targeted nature of DOX (Ferreira et al. 2017), future studies could also elucidate the role of this drug on AceCS2 activity (Hallows et al. 2006). In turn, the reversal of oscillation in BMAL1 acetylation between ZT 9 and ZT 21 in mice and the increased BMAL1 deacetylation observed in the cell culture treatments may eventually affect the downstream expression of clock-controlled genes, since Bmal1 deacetylation leads to repression of target genes expression. Importantly, even in SIRT1 knockout MEFs it was possible to observe a reduction of acetylation in DOX-treated cells, which suggests that other sirtuins may be involved. An overall increase in lysine-acetylated proteins was observed in $\mathrm{H} 9 \mathrm{c} 2$ cardiomyoblasts and in hearts of DOX-treated mice, with those differences attributed to reduced SIRT1- and SIRT3 levels (Cheung et al. 2015). However, although a general increase in acetylation may be possible in response to signaling pathways or metabolic remodeling, our results suggest that DOX treatment also leads to a selective increase in the activity of sirtuin(s). Another report observed increased $\mathrm{H} 3$ deacetylation induced by DOX, suggesting activation of SIRT1, and it was suggested that it could be a compensatory mechanism to respond to oxidative stress (Danz et al. 2009).

In conclusion, the present study reveals that DOX treatment in mice during the first weeks of age has detrimental effects on oscillatory molecular mechanisms including gene expression-rhythmicity and acetylation profiles, which are biologically related. If confirmed in humans, these results suggest that treatment with cardiotoxic agents during childhood may compromise the circadian mechanisms and daily rhythmicity of the heart, which can contribute to the manifestation of cardiovascular disease later in life.

Acknowledgements This work was funded by FEDER funds through the Operational Program for Competitiveness FactorsCOMPETE and national funds by FCT-Foundation for Science and Technology under research Grant PTDC/DTP-FTO/2433/2014 (POCI-01-0145-FEDER-016659), PTDC/BTM-SAL/29297/2017
(POCI-01-0145-FEDER-029297), and UID/NEU/04539/2019. Supported also by QREN project 4832 with reference CENTRO- 07-ST24FEDER-002008 financed through FEDER. LF was supported by an FCT PhD-fellowship (SFRH/BD/ 52429/2013), and TC-O was supported by Grant POCI-01-0145-FEDER-029297.

Author contributions LF and PC designed the experiments. LF conducted the experiments and collected the data with early technical assistance from MC. Raw sequencing data was analyzed by HF and CE. LF analyzed the data, wrote the manuscript, and prepared all figures. TO finalized the manuscript. LF, PO, TO, MC, and PC reviewed the manuscript.

\section{Compliance with ethical standards}

Conflict of interest The authors declare that they have no conflict of interest.

\section{References}

Alcendor RR, Gao S, Zhai P et al (2007) Sirt1 regulates aging and resistance to oxidative stress in the heart. Circ Res 100:15121521. https://doi.org/10.1161/01.RES.0000267723.65696.4a

Asher G, Gatfield D, Stratmann M et al (2008) SIRT1 regulates circadian clock gene expression through PER2 deacetylation. Cell 134:317-328. https://doi.org/10.1016/j.cell.2008.06.050

Balsalobre A, Damiola F, Schibler U (1998) A serum shock induces circadian gene expression in mammalian tissue culture cells. Cell 93:929-937

Balsalobre A, Brown SA, Marcacci L et al (2000) Resetting of circadian time in peripheral tissues by glucocorticoid signaling. Science 289:2344-2347. https://doi.org/10.1126/science.289.5488.2344

Bansal N, Amdani S, Lipshultz ER, Lipshultz SE (2017) Chemotherapy-induced cardiotoxicity in children. Expert Opin Drug Metab Toxicol 13:817-832. https://doi.org/10.1080/17425 255.2017.1351547

Bechtold DA, Gibbs JE, Loudon AS (2010) Circadian dysfunction in disease. Trends Pharmacol Sci 31:191-198. https://doi. org/10.1016/j.tips.2010.01.002

Bellet MM, Nakahata Y, Boudjelal M et al (2013) Pharmacological modulation of circadian rhythms by synthetic activators of the deacetylase SIRT1. Proc Natl Acad Sci USA 110:3333-3338. https://doi.org/10.1073/pnas.1214266110

Berthiaume JM, Wallace KB (2007) Persistent alterations to the gene expression profile of the heart subsequent to chronic Doxorubicin treatment. Cardiovasc Toxicol 7:178-191. https://doi.org/10.1007/ s12012-007-0026-0

Bonnefont JP, Djouadi F, Prip-Buus C, Gobin S, Munnich A, Bastin $\mathrm{J}$ (2004) Carnitine palmitoyltransferases 1 and 2: biochemical, molecular and medical aspects. Mol Aspects Med 25:495-520. https://doi.org/10.1016/j.mam.2004.06.004

Buhr ED, Takahashi JS (2013) Molecular components of the Mammalian circadian clock. Handb Exp Pharmacol. 3-27. https://doi. org/10.1007/978-3-642-25950-0_1

Carvalho FS, Burgeiro A, Garcia R, Moreno AJ, Carvalho RA, Oliveira PJ (2014) Doxorubicin-induced cardiotoxicity: from bioenergetic failure and cell death to cardiomyopathy. Med Res Rev 34:106135. https://doi.org/10.1002/med.21280

Cheng HL, Mostoslavsky R, Saito S et al (2003) Developmental defects and p53 hyperacetylation in Sir2 homolog (SIRT1)-deficient mice. Proc Natl Acad Sci USA 100:10794-10799. https://doi. org/10.1073/pnas. 1934713100 
Cheung KG, Cole LK, Xiang B et al (2015) Sirtuin-3 (SIRT3) protein attenuates doxorubicin-induced oxidative stress and improves mitochondrial respiration in $\mathrm{H} 9 \mathrm{c} 2$ cardiomyocytes. J Biol Chem 290:10981-10993. https://doi.org/10.1074/jbc.M114.607960

Cho H, Zhao X, Hatori M et al (2012) Regulation of circadian behaviour and metabolism by REV-ERB-alpha and REV-ERB-beta. Nature 485:123-127. https://doi.org/10.1038/nature11048

Cui L, Guo J, Zhang Q et al (2017) Erythropoietin activates SIRT1 to protect human cardiomyocytes against doxorubicin-induced mitochondrial dysfunction and toxicity. Toxicol Lett 275:28-38. https://doi.org/10.1016/j.toxlet.2017.04.018

Danz ED, Skramsted J, Henry N, Bennett JA, Keller RS (2009) Resveratrol prevents doxorubicin cardiotoxicity through mitochondrial stabilization and the Sirt1 pathway. Free Radic Biol Med 46:15891597. https://doi.org/10.1016/j.freeradbiomed.2009.03.011

Del Ry S, Cabiati M, Clerico A (2014) Natriuretic peptide system and the heart. Front Horm Res 43:134-143. https://doi. org/10.1159/000360597

Dyar KA, Lutter D, Artati A et al (2018) Atlas of circadian metabolism reveals system-wide coordination and communication between clocks. Cell 174(1571-1585):e1511. https://doi.org/10.1016/j. cell.2018.08.042

Ekstein S, Nir A, Rein AJ et al (2007) N-terminal-proB-type natriuretic peptide as a marker for acute anthracycline cardiotoxicity in children. J Pediatr Hematol Oncol 29:440-444. https://doi. org/10.1097/MPH.0b013e3180640d42

Ferreira A, Cunha-Oliveira T, Simoes RF et al (2017) Altered mitochondrial epigenetics associated with subchronic doxorubicin cardiotoxicity. Toxicology 390:63-73. https://doi.org/10.1016/j.tox.2017.08.011

Filiano AN, Millender-Swain T, Johnson R Jr, Young ME, Gamble KL, Bailey SM (2013) Chronic ethanol consumption disrupts the core molecular clock and diurnal rhythms of metabolic genes in the liver without affecting the suprachiasmatic nucleus. PLoS ONE 8:e71684. https://doi.org/10.1371/journal.pone.0071684

Gertz M, Fischer F, Nguyen GT, Lakshminarasimhan M, Schutkowski M, Weyand M, Steegborn C (2013) Ex-527 inhibits Sirtuins by exploiting their unique NAD+-dependent deacetylation mechanism. Proc Natl Acad Sci USA 110:E2772-2781. https://doi. org/10.1073/pnas.1303628110

Ghibu S, Delemasure S, Richard C et al (2012) General oxidative stress during doxorubicin-induced cardiotoxicity in rats: absence of cardioprotection and low antioxidant efficiency of alpha-lipoic acid. Biochimie 94:932-939. https://doi.org/10.1016/j.bioch i. 2011.02 .015

Granda TG, Filipski E, D’Attino RM, Vrignaud P, Anjo A, Bissery MC, Levi F (2001) Experimental chronotherapy of mouse mammary adenocarcinoma MA13/C with docetaxel and doxorubicin as single agents and in combination. Cancer Res 61:1996-2001

Hallows WC, Lee S, Denu JM (2006) Sirtuins deacetylate and activate mammalian acetyl-CoA synthetases. Proc Natl Acad Sci USA 103:10230-10235. https://doi.org/10.1073/pnas.0604392103

Heart EA, Karandrea S, Liang X et al (2016) Mechanisms of Doxorubicin Toxicity in Pancreatic beta-Cells. Toxicol Sci 152:395-405. https://doi.org/10.1093/toxsci/kfw096

Hirayama J, Sahar S, Grimaldi B, Tamaru T, Takamatsu K, Nakahata Y, Sassone-Corsi P (2007) CLOCK-mediated acetylation of BMAL1 controls circadian function. Nature 450:1086-1090. https ://doi.org/10.1038/nature06394

Huang Y, Walstrom A, Zhang L, Zhao Y, Cui M, Ye L, Zheng JC (2009) Type I interferons and interferon regulatory factors regulate TNF-related apoptosis-inducing ligand (TRAIL) in HIV-1-infected macrophages. PLoS ONE 4:e5397. https://doi.org/10.1371/ journal.pone.0005397

Huang C, Zhang X, Ramil JM et al (2010) Juvenile exposure to anthracyclines impairs cardiac progenitor cell function and vascularization resulting in greater susceptibility to stress-induced myocardial injury in adult mice. Circulation 121:675-683. https:// doi.org/10.1161/CIRCULATIONAHA.109.902221

Kim TK, Kim T, Kim TY, Lee WG, Yim J (2000) Chemotherapeutic DNA-damaging drugs activate interferon regulatory factor-7 by the mitogen-activated protein kinase kinase-4-cJun NH2-terminal kinase pathway. Cancer Res 60:1153-1156

Knutsson A, Akerstedt T, Jonsson BG, Orth-Gomer K (1986) Increased risk of ischaemic heart disease in shift workers. Lancet 2:89-92. https://doi.org/10.1016/s0140-6736(86)91619-3

Kohsaka A, Das P, Hashimoto I et al (2014) The circadian clock maintains cardiac function by regulating mitochondrial metabolism in mice. PLoS ONE 9:e112811. https://doi.org/10.1371/journ al.pone. 0112811

Langenickel T, Pagel I, Hohnel K, Dietz R, Willenbrock R (2000) Differential regulation of cardiac ANP and BNP mRNA in different stages of experimental heart failure. Am J Physiol Heart Circ Physiol 278:H1500-1506. https://doi.org/10.1152/ajphe art.2000.278.5.H1500

Langmead B, Salzberg SL (2012) Fast gapped-read alignment with Bowtie 2. Nat Methods 9:357-359. https://doi.org/10.1038/nmeth .1923

Lebrecht D, Kokkori A, Ketelsen UP, Setzer B, Walker UA (2005) Tissue-specific mtDNA lesions and radical-associated mitochondrial dysfunction in human hearts exposed to doxorubicin. J Pathol 207:436-444. https://doi.org/10.1002/path.1863

Lipshultz SE, Miller TL, Scully RE et al (2012) Changes in cardiac biomarkers during doxorubicin treatment of pediatric patients with high-risk acute lymphoblastic leukemia: associations with longterm echocardiographic outcomes. J Clin Oncol 30:1042-1049. https://doi.org/10.1200/JCO.2010.30.3404

Litinski M, Scheer FA, Shea SA (2009) Influence of the circadian system on disease severity. Sleep Med Clin 4:143-163. https://doi. org/10.1016/j.jsmc.2009.02.005

Liu MH, Shan J, Li J, Zhang Y, Lin XL (2016) Resveratrol inhibits doxorubicin-induced cardiotoxicity via sirtuin 1 activation in H9c2 cardiomyocytes. Exp Ther Med 12:1113-1118. https://doi. org/10.3892/etm.2016.3437

Lupertz R, Watjen W, Kahl R, Chovolou Y (2010) Dose- and timedependent effects of doxorubicin on cytotoxicity, cell cycle and apoptotic cell death in human colon cancer cells. Toxicology 271:115-121. https://doi.org/10.1016/j.tox.2010.03.012

Maejima Y, Adachi S, Ito H, Hirao K, Isobe M (2008) Induction of premature senescence in cardiomyocytes by doxorubicin as a novel mechanism of myocardial damage. Aging Cell 7:125-136. https ://doi.org/10.1111/j.1474-9726.2007.00358.x

Masri S, Sassone-Corsi P (2014) Sirtuins and the circadian clock: bridging chromatin and metabolism. Sci Signal 7:re6. https://doi. org/10.1126/scisignal.2005685

Mericskay M (2016) Nicotinamide adenine dinucleotide homeostasis and signalling in heart disease: Pathophysiological implications and therapeutic potential. Arch Cardiovasc Dis 109:207-215. https://doi.org/10.1016/j.acvd.2015.10.004

Mistry P, Duong A, Kirshenbaum L, Martino TA (2017) Cardiac clocks and preclinical translation. Heart Fail Clin 13:657-672. https:// doi.org/10.1016/j.hfc.2017.05.002

Mulrooney DA, Yeazel MW, Kawashima T et al (2009) Cardiac outcomes in a cohort of adult survivors of childhood and adolescent cancer: retrospective analysis of the Childhood Cancer Survivor Study cohort. BMJ 339:b4606. https://doi.org/10.1136/ bmj.b4606

Nakahata Y, Kaluzova M, Grimaldi B et al (2008) The NAD+dependent deacetylase SIRT1 modulates CLOCK-mediated chromatin remodeling and circadian control. Cell 134:329-340. https://doi.org/10.1016/j.cell.2008.07.002 
Nakahata Y, Sahar S, Astarita G, Kaluzova M, Sassone-Corsi P (2009) Circadian control of the NAD+ salvage pathway by CLOCK-SIRT1. Science 324:654-657. https://doi.org/10.1126/ science. 1170803

Nemoto S, Fergusson MM, Finkel T (2005) SIRT1 functionally interacts with the metabolic regulator and transcriptional coactivator PGC-1 \{alpha\}. J Biol Chem 280:16456-16460. https://doi. org/10.1074/jbc.M501485200

Nordgren KKS, Hampton M, Wallace KB (2017) Editor's highlight: the altered DNA methylome of chronic doxorubicin exposure in sprague dawley rats. Toxicol Sci 159:470-479. https://doi. org/10.1093/toxsci/kfx 150

O'Connell JL, Romano MM, Campos Pulici EC et al (2017) Shortterm and long-term models of doxorubicin-induced cardiomyopathy in rats: a comparison of functional and histopathological changes. Exp Toxicol Pathol 69:213-219. https://doi. org/10.1016/j.etp.2017.01.004

Osman AM, Al-Harthi SE, AlArabi OM et al (2013) Chemosensetizing and cardioprotective effects of resveratrol in doxorubicin- treated animals. Cancer Cell Int 13:52. https://doi. org/10.1186/1475-2867-13-52

Peek CB, Affinati AH, Ramsey KM et al (2013) Circadian clock NAD+ cycle drives mitochondrial oxidative metabolism in mice. Science 342:1243417. https://doi.org/10.1126/scien ce. 1243417

Pillai VB, Bindu S, Sharp W et al (2016) Sirt3 protects mitochondrial DNA damage and blocks the development of doxorubicininduced cardiomyopathy in mice. Am J Physiol Heart Circ Physiol 310:H962-972. https://doi.org/10.1152/ajpheart.00832.2015

Piotrowska I, Isalan M, Mielcarek M (2017) Early transcriptional alteration of histone deacetylases in a murine model of doxorubicin-induced cardiomyopathy. PLoS ONE 12:e0180571. https ://doi.org/10.1371/journal.pone.0180571

Richard C, Ghibu S, Delemasure-Chalumeau S et al (2011) Oxidative stress and myocardial gene alterations associated with Doxorubicin-induced cardiotoxicity in rats persist for 2 months after treatment cessation. J Pharmacol Exp Ther 339:807-814. https://doi.org/10.1124/jpet.111.185892

Sacco G, Giampietro R, Salvatorelli E et al (2003) Chronic cardiotoxicity of anticancer anthracyclines in the rat: role of secondary metabolites and reduced toxicity by a novel anthracycline with impaired metabolite formation and reactivity. Br J Pharmacol 139:641-651. https://doi.org/10.1038/sj.bjp.0705270

Sahar S, Masubuchi S, Eckel-Mahan K et al (2014) Circadian control of fatty acid elongation by SIRT1 protein-mediated deacetylation of acetyl-coenzyme A synthetase 1. J Biol Chem 289:60916097. https://doi.org/10.1074/jbc.M113.537191

Schmieder R, Lim YW, Edwards R (2012) Identification and removal of ribosomal RNA sequences from metatranscriptomes. Bioinformatics 28:433-435. https://doi.org/10.1093/bioinformatics/btr669

Sengupta S, Yang G, O'Donnell JC et al (2016) The circadian gene Rev-erbalpha improves cellular bioenergetics and provides preconditioning for protection against oxidative stress. Free Radic Biol Med 93:177-189. https://doi.org/10.1016/j.freeradbio med.2016.02.004

Silva FSG, Starostina IG, Ivanova VV, Rizvanov AA, Oliveira PJ, Pereira SP (2016) Determination of metabolic viability and cell mass using a tandem resazurin/sulforhodamine B assay. Curr Protoc Toxicol 68:2.24.21-22.24.15. https://doi.org/10.1002/ cptx.1

Siu WY, Yam CH, Poon RY (1999) G1 versus G2 cell cycle arrest after adriamycin-induced damage in mouse Swiss3T3 cells. FEBS Lett 461:299-305. https://doi.org/10.1016/s0014 $-5793(99) 01481-7$

Sothern RB, Levi F, Haus E, Halberg F, Hrushesky WJ (1989) Control of a murine plasmacytoma with doxorubicin-cisplatin: dependence on circadian stage of treatment. J Natl Cancer Inst 81:135-145. https://doi.org/10.1093/jnci/81.2.135

Takei Y, Inoue K, Trajanovska S, Donald JA (2011) B-type natriuretic peptide (BNP), not ANP, is the principal cardiac natriuretic peptide in vertebrates as revealed by comparative studies. Gen Comp Endocrinol 171:258-266. https://doi.org/10.1016/j.ygcen.2011.02.021

Terrand J, Xu B, Morrissy S, Dinh TN, Williams S, Chen QM (2011) p21(WAF1/Cip1/Sdi1) knockout mice respond to doxorubicin with reduced cardiotoxicity. Toxicol Appl Pharmacol 257:102110. https://doi.org/10.1016/j.taap.2011.08.024

Travnickova-Bendova Z, Cermakian N, Reppert SM, SassoneCorsi P (2002) Bimodal regulation of mPeriod promoters by CREB-dependent signaling and CLOCK/BMAL1 activity. Proc Natl Acad Sci U S A 99:7728-7733. https://doi.org/10.1073/ pnas. 102075599

Tsimakouridze EV, Alibhai FJ, Martino TA (2015) Therapeutic applications of circadian rhythms for the cardiovascular system. Front Pharmacol 6:77. https://doi.org/10.3389/fphar.2015.00077

van Dalen EC, van der Pal HJ, Kok WE, Caron HN, Kremer LC (2006) Clinical heart failure in a cohort of children treated with anthracyclines: a long-term follow-up study. Eur J Cancer 42:3191-3198. https://doi.org/10.1016/j.ejca.2006.08.005

Wang S, Song P, Zou MH (2012) Inhibition of AMP-activated protein kinase alpha (AMPKalpha) by doxorubicin accentuates genotoxic stress and cell death in mouse embryonic fibroblasts and cardiomyocytes: role of p53 and SIRT1. J Biol Chem 287:8001-8012. https://doi.org/10.1074/jbc.M111.315812

Wang B, Ma Y, Kong X, Ding X, Gu H, Chu T, Ying W (2014) $\mathrm{NAD}(+)$ administration decreases doxorubicin-induced liver damage of mice by enhancing antioxidation capacity and decreasing DNA damage. Chem Biol Interact 212:65-71. https ://doi.org/10.1016/j.cbi.2014.01.013

Wang S, Wang Y, Zhang Z, Liu Q, Gu J (2017) Cardioprotective effects of fibroblast growth factor 21 against doxorubicininduced toxicity via the SIRT1/LKB1/AMPK pathway. Cell Death Dis 8:e3018. https://doi.org/10.1038/cddis.2017.410

West AC, Smith L, Ray DW, Loudon ASI, Brown TM, Bechtold DA (2017) Misalignment with the external light environment drives metabolic and cardiac dysfunction. Nat Commun 8:417. https:// doi.org/10.1038/s41467-017-00462-2

Yang G, Wright CJ, Hinson MD et al (2014) Oxidative stress and inflammation modulate Rev-erbalpha signaling in the neonatal lung and affect circadian rhythmicity. Antioxid Redox Signal 21:17-32. https://doi.org/10.1089/ars.2013.5539

Young ME, Bray MS (2007) Potential role for peripheral circadian clock dyssynchrony in the pathogenesis of cardiovascular dysfunction. Sleep Med 8:656-667. https://doi.org/10.1016/j.sleep .2006.12.010

Yuan YP, Ma ZG, Zhang X et al (2018) CTRP3 protected against doxorubicin-induced cardiac dysfunction, inflammation and cell death via activation of Sirt1. J Mol Cell Cardiol 114:38-47. https://doi.org/10.1016/j.yjmcc.2017.10.008

Zhang C, Feng Y, Qu S et al (2011) Resveratrol attenuates doxorubicin-induced cardiomyocyte apoptosis in mice through SIRT1mediated deacetylation of p53. Cardiovasc Res 90:538-545. https://doi.org/10.1093/cvr/cvr022

Zhu W, Shou W, Payne RM, Caldwell R, Field LJ (2008) A mouse model for juvenile doxorubicin-induced cardiac dysfunction. Pediatr Res 64:488-494. https://doi.org/10.1203/PDR.0b013 e318184d732

Zhu JN, Fu YH, Hu ZQ et al (2017) Activation of miR-34a-5p/Sirt1/ p66shc pathway contributes to doxorubicin-induced cardiotoxicity. Sci Rep 7:11879. https://doi.org/10.1038/s41598-017-12192-y

Publisher's Note Springer Nature remains neutral with regard to jurisdictional claims in published maps and institutional affiliations. 